\title{
Identification of a Neurite Outgrowth-Promoting Motif within the Alternatively Spliced Region of Human Tenascin-C
}

\author{
Sally Meiners, Mohammed S.A. Nur-e-Kamal, and Mary Lynn T. Mercado \\ Department of Pharmacology, University of Medicine and Dentistry of New Jersey, Robert Wood Johnson Medical \\ School, Piscataway, New Jersey 08854
}

\begin{abstract}
Our work centers on understanding how the extracellular matrix molecule tenascin-C regulates neuronal growth. We have found that the region of tenascin-C containing only alternately spliced fibronectin type-III repeat $\mathrm{D}$, called $\mathrm{fnD}$, when used by itself, dramatically increases neurite outgrowth in culture. We used overlapping synthetic peptides to localize the neurite outgrowth-promoting site within fnD to a 15 amino acid sequence, called D5. An antibody against D5 blocked promotion of neurite outgrowth by $\mathrm{fnD}$ as well as tenascin- $\mathrm{C}$, indicating that this peptide sequence is functional in the context of the native molecule. Further testing of shorter synthetic peptides restricted the neurite outgrowth-promoting site to eight amino acids, VFDNFVLK. Of these, "FD" and "FV" are conserved in tenascin- $C$ sequences derived from all the species available in the GenBank. To investigate the hypothesis that FD and FV are
\end{abstract}

critical for the interaction with neurons, we tested a recombinant fnD protein and synthetic peptides with alterations in FD and/or FV. These molecules did not facilitate process extension, suggesting that the conserved amino acids are required for formation of the active site in fnD. We next investigated whether VFDNFVLK could be used as a reagent to overcome the neurite outgrowth inhibitory properties of chondroitin sulfate proteoglycans, the major inhibitory molecules in the glial scar. The peptide significantly enhanced outgrowth on proteoglycans and was more effective than laminin-1, L1-Fc, or intact tenascin-C, thus demonstrating the potential applicability of tenascin-C regions as therapeutic reagents.

Key words: tenascin-C; FN-III repeat; alternatively spliced region; synthetic peptide; site-directed modifications; neurite outgrowth
The extracellular matrix molecule tenascin- $\mathrm{C}$ is not a single molecule but is instead a family of alternatively spliced variants that have major actions to modulate neuronal growth and migration (Grumet et al., 1985; Bronner-Fraser, 1988; Gates et al., 1996). Tenascin-C splice variants differ only in their number of fibronectin type III (FN-III) repeats; for example, the largest splice variant of human tenascin- $\mathrm{C}$ has seven alternatively spliced FN-III repeats (designated fnA-D) that are missing in the smallest. Phases of increased cell migration and axonal growth in the developing CNS have been closely correlated with expression of large but not small tenascin-C (Steindler et al., 1989; Crossin et al., 1989; Prieto et al., 1990; Kaplony et al., 1991; Bartsch et al., 1992; Tucker, 1993), suggesting that the fnA-D repeats might facilitate cell and neurite motility during embryogenesis, and perhaps after injury as well.

We have demonstrated previously that fnA-D can promote both neurite outgrowth and axonal guidance through different parts of the molecule: the FN-III repeat $\mathrm{C}(\mathrm{fnC})$ appears to be essential for promotion of neurite guidance (Meiners et al., 1999a), whereas fnD is responsible for promotion of neurite

\footnotetext{
Received Feb. 26, 2001; revised June 18, 2001; accepted June 28, 2001.

This work was supported in part by National Institute of Environmental Health Services Exploratory Research Award RQ1610, Paralyzed Veterans of America Spinal Cord Research Foundation Grant 2148, and National Institutes of Health Grant R01 NS40394 to S.M. We thank Dr. Herbert M. Geller for constant support and helpful discussions; Dr. Harold Erickson for helpful discussions and the gift of transfected BHK cells, recombinant fn6-8 protein, and polyclonal fn6-8/fbg antibody; Dr. Melitta Schachner for helpful discussions and the gift of L1-Fc; and Dr. Andreas Faissner for helpful discussions.

Correspondence should be addressed to Dr. Sally Meiners, Department of Pharmacology, University of Medicine and Dentistry of New Jersey, Robert Wood Johnson Medical School, 675 Hoes Lane, Piscataway, NJ 08854. E-mail: meiners@umdnj.edu.
}

Copyright (C) 2001 Society for Neuroscience $\quad 0270-6474 / 01 / 217215-11 \$ 15.00 / 0$ outgrowth (Gotz et al., 1996; Meiners and Geller, 1997; Meiners et al., 1999a). Each of these repeats is $\sim 90$ amino acids in length. However, studies of other matrix molecules have localized functional regions to shorter stretches of amino acids. For example, the sequence SIKVAV is responsible for neurite outgrowth promotion by the $\alpha 1$ helical domain of laminin-1 (Sephel et al., 1989). Furthermore, the sequence PHSRN in the ninth FN-III repeat of fibronectin synergizes with RGD in the tenth FN-III repeat to enhance cell adhesive function (Aota et al., 1994). We therefore investigated the hypothesis that a short linear amino acid sequence is similarly responsible for neurite outgrowth promotion by $\mathrm{fnD}$.

We used a series of overlapping synthetic peptides covering the 91 amino acid sequence of fnD in assays that were previously used to demonstrate the ability of fnA-D to promote neurite outgrowth (Meiners and Geller, 1997). This strategy led to the identification of an eight amino acid sequence, VFDNFVLK, that can, by itself, promote process extension. Further experiments supported the hypothesis that this sequence is functional in native tenascin-C and that the amino acids "FD" and "FV," which are conserved in tenascin- $\mathrm{C}$ derived from all vertebrate species, are essential for the formation of the neurite outgrowth-promoting motif in fnD. This is the most precise localization of a neurite outgrowth regulatory region within tenascin-C. Moreover, because small peptides have potential application in therapeutic strategies (Sakiyama et al., 1999; Pavia et al., 2000), we evaluated whether VFDNFVLK was able to overcome the neuronal growth inhibitory properties of chondroitin sulfate proteoglycans (CSPGs). CSPGs are upregulated in the glial scar and are strongly repellant to growing axons (McKeon et al., 1991; Pindzola et al., 1993; Zuo et al., 1998; Fernaud-Espinosa et al., 1998). 


\begin{tabular}{|c|c|c|}
\hline Peptide & Sequence & $\begin{array}{l}\text { Coating efficiency } \\
\left(\mathrm{pmol} / \mathrm{cm}^{2}\right)\end{array}$ \\
\hline D1 & EAEPEVDNLLVSDAT & $7.8 \pm 1.4$ \\
\hline $\mathrm{D} 2$ & NLLVSDATPDGFRLS & $8.3 \pm 0.4$ \\
\hline D3 & TPDGFRLSWTADEGV & $4.7 \pm 0.2$ \\
\hline D4 & SWTADEGVFDNFVLK & $5.2 \pm 1.1$ \\
\hline D5 & VFDNFVLKIRDTKKQ & $7.4 \pm 0.8$ \\
\hline D6 & IRDTKKQSEPLEITL & $9.7 \pm 1.3$ \\
\hline D7 & QSEPLEITLLAPERT & $5.1 \pm 1.7$ \\
\hline D8 & ITLLAPERTRDLTGL & $10.1 \pm 1.4$ \\
\hline D9 & TRDLTGLREATEYEI & $3.6 \pm 0.8$ \\
\hline D10 & REATEYEIELYGISK & $12.4 \pm 2.5$ \\
\hline D11 & IELYGISKGRRSQTV & $6.5 \pm 0.9$ \\
\hline D12 & SKGRRSQTVSAIATT & $7.6 \pm 1.2$ \\
\hline
\end{tabular}

PLL-coated glass coverslips were coated with fluorescein-conjugated peptides as indicated. At least three singular measurements were performed per peptide, and values obtained in three separate experiments were pooled and used for the determination of SDs.

Our data indicate that VFDNFVLK or its derivatives may find utility in strategies to promote axonal regeneration after injury.

\section{MATERIALS AND METHODS}

Proteins and antibodies. Synthetic overlapping 15 amino acid and 8 amino acid peptides covering the sequence of fnD that is derived from human tenascin-C (Table 1) and rabbit affinity-purified polyclonal antibody against the D5 peptide were prepared by BioSynthesis (Lewisville, TX). Peptides were characterized by BioSynthesis by mass spectral analysis and HPLC tracing. Transfected baby hamster kidney (BHK) cells, recombinant fn6-8 protein expressed in bacteria corresponding to universal FN-III repeats 6-8, and rabbit polyclonal fn6-8/fbg antibody were gifts of Dr. Harold Erickson (Department of Cell Biology, Duke University Medical Center, Durham, NC). Splice variants of human tenascin-C were produced in the transfected cells (Aukhil et al., 1993). Native large and small tenascin-C were purified from culture supernatants of these cells by gelatin-Sepharose and hydroxyapatite chromatography (Aukhil et al., 1993; Erickson and Briscoe, 1995) followed by electroelution from nondenaturing gels (S. Meiners, unpublished data). Recombinant fn6-8 protein was produced using the PCR and cDNA derived from BHK cells transfected with large tenascin-C as the template. Rabbit polyclonal fn6-8/fbg antibody was prepared against a mixture of fn6-8 and fbg (fibrinogen knob) (see Fig. 1) recombinant proteins. All reagents cited correspond to the human protein.

Laminin-1 was obtained from Life Technologies (Rockville, MD). Neural adhesion molecule L1 fused to the Fc region of human immunoglobulin (L1-Fc) was the gift of Dr. Melitta Schachner (Center for Molecular Neurobiology, University of Hamburg, Hamburg, Germany). CSPG mixture isolated from embryonic chick brain (consisting primarily of neurocan, phosphacan, versican, and aggrecan) was obtained from Chemicon (Temecula, CA).

Construction of wild-type and mutant recombinant FnD proteins. For the wild-type construct, the $\mathrm{fnD}$ region of the human tenascin- $\mathrm{C}$ gene was amplified using PCR. We used cDNA that was derived from BHK cells transfected with large tenascin- $\mathrm{C}$ as the template and fnD-S1 (sense, $5^{\prime}$ GAA TTC GAA GCC GAA CCG GAA GTT 3') and fnD-A1 (antisense, 5' AAG CTT TTA TGT TGT TGC TAT AGC ACT $3^{\prime}$ ) as the primers. Mutant fnD was constructed by oligonucleotide-directed PCR mutagenesis. Two PCR reactions were performed for making the mutant. For the first PCR reaction, the $5^{\prime}$ end and the $3^{\prime}$ end of $\mathrm{fnD}$ were amplified separately using fnD-S1 (sense)/fnD-A2 (antisense, 5' GAC CCC TTC ATC AGC TGT 3') and fnD-S2 (sense, 5' ACA GCT GAT GAA GGG GTC AGT CCT AAT GGC TCC CTC AAA ATC AGA GAT ACC $3^{\prime}$ )/fnD-A1 (antisense). For the second PCR reaction, small amounts of gel-purified $5^{\prime}$ and $3^{\prime}$ PCR end products were mixed and amplified by PCR using fnD-S1 and fnD-A1 primers to fuse both parts of $\mathrm{fnD}$. The fnD-S1 and fnD-A1 primers were designed in such a way that EcoRI and HindIII restriction sites were created at the 5' and $3^{\prime}$ ends of the fnD construct, respectively, whereas the fnD-S1 primer was designed to create a mutant protein in which amino acid sequence FDNFV of fnD was replaced by SPNGS.

The wild-type and mutant fnD constructs were subjected to nucleotide sequencing to confirm the correct sequences. They were then digested by EcoRI and HindIII and ligated into the pGEX-2TH vector as described previously (Nur-e-kamal et al., 1993). Ligated plasmids were transformed into Escherichia coli, selected on ampicillin plates, and characterized by restriction digestion and nucleotide sequencing. Those having the correct insert and orientation were expressed as GST-fusion proteins, purified on a glutathione Sepharose column, and then cleaved with thrombin (Sigma, St. Louis, MO) as described (Nur-e-kamal et al., 1993).

Neuronal cell culture. Cerebellar granule neuronal cultures were prepared as described from postnatal day (P) 8 rat pups (Meiners et al., 1999a). Cerebral cortical neurons were prepared from embryonic day (E) 17 rat pups (Meiners and Geller, 1997). Postnatal or embryonic brains were removed into a Petri dish containing $5 \mathrm{ml}$ of Basal Medium Eagle (BME) with $10 \mathrm{mM}$ HEPES buffer (BME-HEPES). The selected brain region (cerebellum or cerebral cortex) was removed, and meninges and blood vessels were peeled off and discarded to ensure minimal contamination from endothelial cells. The brain tissue was then minced into fine pieces $(<0.5 \mathrm{~mm})$ with dissecting knives and incubated in BME-HEPES containing $0.025 \%$ trypsin for $10 \mathrm{~min}$ at $37^{\circ} \mathrm{C}$. After incubation, the trypsinization was halted by adding $1 \mathrm{ml}$ of BME containing $0.025 \%$ soybean trypsin inhibitor and $0.05 \%$ DNase I. Then, the tissue was triturated gently through a fire-polished Pasteur pipette until it was dispersed into a homogeneous suspension. Cells were centrifuged for 10 $\mathrm{min}$ at $1500 \mathrm{rpm}$, filtered through an ethanol-sterilized $40 \mu \mathrm{m}$ mesh (Sefar America, Kansas City, MO), and resuspended in DMEM supplemented with $\mathrm{N} 2[10 \mu \mathrm{g} / \mathrm{ml}$ transferrin, $2 \mu \mathrm{g} / \mathrm{ml}$ putrescine, $50 \mathrm{ng} / \mathrm{ml}$ bovine insulin, $10 \mu \mathrm{g} / \mathrm{ml}$ bovine serum albumin, $40 \mathrm{ng} / \mathrm{ml}$ thyroxine (T4), $30 \mathrm{ng} / \mathrm{ml}$ triiodothyroxine (T3), $6 \mathrm{ng} / \mathrm{ml}$ progesterone, $3 \mathrm{ng} / \mathrm{ml}$ selenium] plus $25 \mathrm{~mm} \mathrm{KCl}$ and $1 \%$ penicillin-streptomycin. The pellet of cerebellar granule or cerebral cortical neurons was resuspended in DMEM/N2/ $\mathrm{KCl}$ and used for neurite outgrowth assays as described below.

Neurite outgrowth assay. To investigate the neurite outgrowthpromoting properties of synthetic 15 amino acid and 8 amino acid peptides, peptides were first dissolved in $1 \%$ acetic acid in double distilled $\mathrm{H}_{2} \mathrm{O}$ at a concentration of $1 \mathrm{mg} / \mathrm{ml}$ and then diluted in DMEM/ $\mathrm{N} 2 / \mathrm{KCl}$ to a concentration of $300 \mathrm{nM}$. Poly-L-lysine (PLL)-coated glass coverslips in 24-well trays were incubated with the diluted peptide solutions overnight at $37^{\circ} \mathrm{C}$. Excess solution was rinsed away with HBSS. Substrate coating efficiencies for the peptides were determined by incubating coverslips overnight with peptides conjugated to NHS-fluorescein (Pierce, Rockford, IL). Then, coated peptides were removed by adding $2 \%$ SDS. The fluorescence of peptides bound to PLL-coated glass was then assessed in a Cytofluor II fluorescence microplate reader (PerSeptive Biosystems, Framingham, MA) as we have described previously for recombinant tenascin-C FN-III proteins and tenascin-C splice variants (Meiners et al., 1999a).

Cerebellar granule or cerebral cortical neurons were plated onto the coverslips containing bound peptides at a density of 60,000 neurons per well and allowed to extend neurites for $24 \mathrm{hr}$ in DMEM/N2/KCl. To study the effects of soluble peptides, peptides were first bound to the coverslips as described above; cerebellar granule neurons were then cultured for $24 \mathrm{hr}$ on the coverslips in medium containing an excess of soluble peptides $(100 \mathrm{~nm})$. The extent of neurite outgrowth was then determined via carboxyfluorescein diacetate (CFDA) labeling (Petroski and Geller, 1994). CFDA (Sigma) intensely stains the soma and all processes of cultured, living neurons. Images of the cultures were captured using a Macintosh Quadra 700 and analyzed with the NIH Image software (available at http://rsb.info.nih.gov/). A sample of 100 neurons with well defined processes greater than one cell soma was considered for each condition. Cultures here and elsewhere were scored by individuals blind to the treatment groups. The length of each primary process and its branches was measured for each neuron, and the total neurite length was calculated as the sum of the lengths of individual neurites.

Antibody-blocking experiments. To test the hypothesis that the D5 peptide sequence is functional in tenascin- $\mathrm{C}$, blocking experiments were conducted using an affinity-purified rabbit polyclonal antibody against D5. FnD or fn6-8 (300 nM in DMEM/N2/KCl) was bound to PLLcoated coverslips overnight at $37^{\circ} \mathrm{C}$, and then excess solution was washed away. Substrate coating efficiencies were determined for these proteins and others in subsequent experiments, as described above and in Meiners et al. (1999a). Coverslips were incubated for $1 \mathrm{hr}$ at $37^{\circ} \mathrm{C}$ with $100 \mu \mathrm{g} / \mathrm{ml}$ 


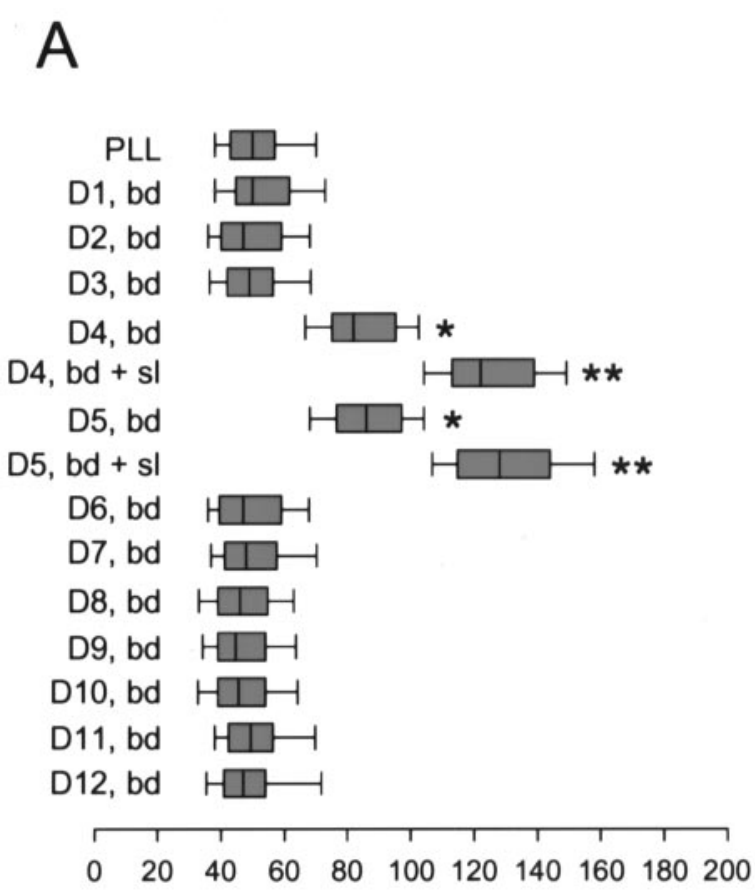

Total neurite length, cerebellar granule neurons $(\mu \mathrm{m})$

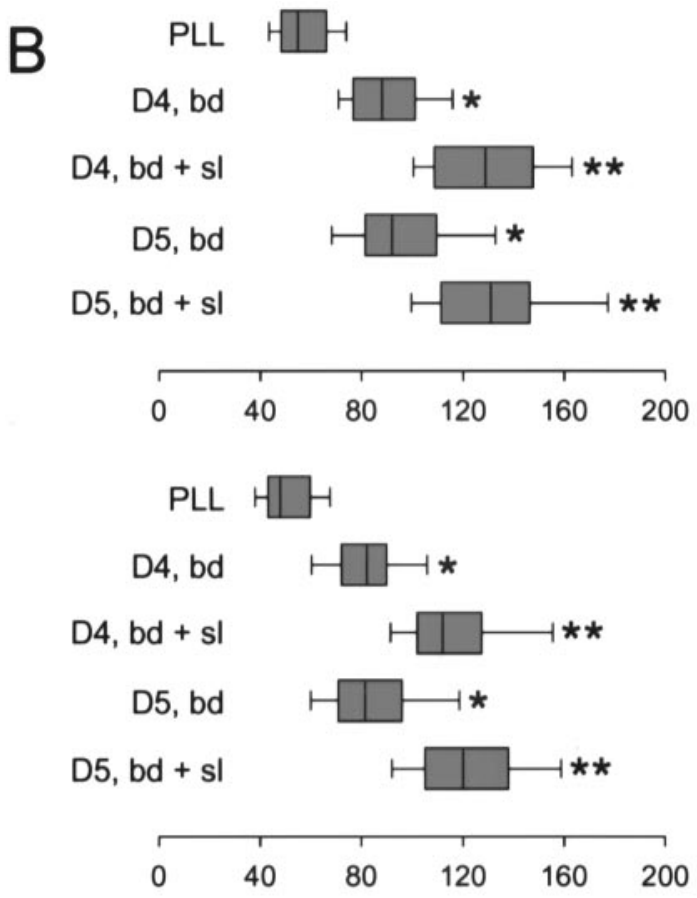

Total neurite length, cerebellar granule neurons $(\mu \mathrm{m})$

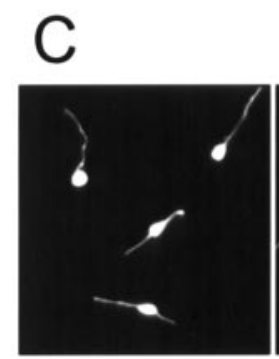

PLL

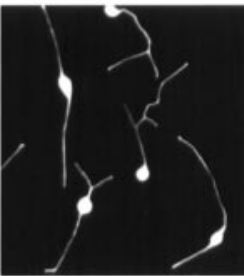

$\mathrm{D} 5, \mathrm{bd}$

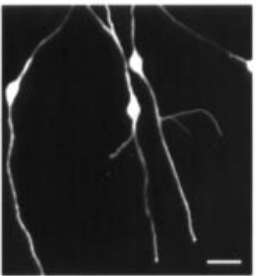

$\mathrm{D} 5, \mathrm{bd}+\mathrm{sl}$
D

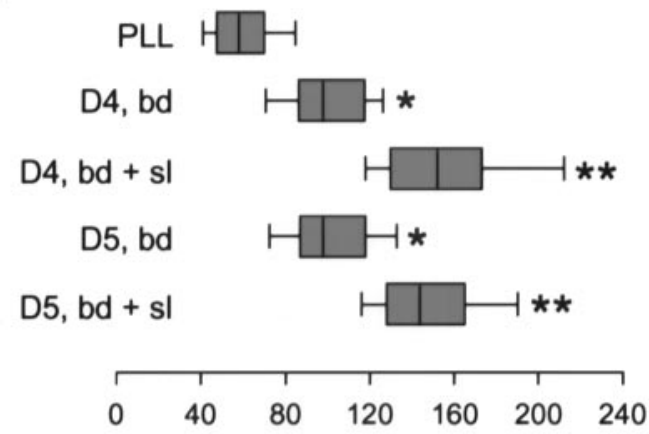

Total neurite length, cerebral cortical neurons $(\mu \mathrm{m})$

Figure 1. Promotion of neurite outgrowth by overlapping 15 amino acid peptides covering the sequence of fnD. $A$, Cerebellar granule neurons were cultured for $24 \mathrm{hr}$ on PLL-coated glass coverslips or PLL-coated glass coverslips in the absence or presence of bound (bd) or bound plus excess soluble $(b d+s l)$ peptides. Distributions of total neurite length are presented as a box-and-whisker plot. Boxes enclose 25 th and 75 th percentiles of each distribution and are bisected by the median; whiskers indicate fifth and 95th percentiles. Two bound peptides, D4 and D5, significantly enhanced outgrowth in comparison to the PLL control. The addition of excess soluble D4 and D5 resulted in a significant further enhancement of outgrowth in comparison to bound D4 and D5 alone. None of the other peptides facilitated neurite outgrowth in either bound (shown) or soluble (data not shown) form. $B$, Two additional independent experiments illustrating the neurite outgrowth-promoting properties of D4 and D5. $C$, Images of cerebellar granule neurons cultured on PLL and D5. Neurites were visibly longer on bound D5 than PLL, and they were longer yet with the addition of soluble D5. Scale bar, $15 \mu \mathrm{m}$. $D$, Cerebral cortical neurons were cultured for $24 \mathrm{hr}$ on PLL-coated coverslips in the absence or presence of bound or bound plus excess soluble D4 or D5. One representative experiment of three is shown. Outgrowth was significantly enhanced on bound D4 and D5 in comparison to PLL $\left({ }^{*} p<0.05\right.$; Kolmogorov-Smirnov test). The addition of excess soluble D4 or D5 resulted in a significant further enhancement of outgrowth in comparison to bound D4 or D5 (**p $<0.05$; Kolmogorov-Smirnov test).

polyclonal D5 antibody, preimmune serum from the rabbit immunized with D5 peptide, or polyclonal fn6-8/fbg antibody in DMEM/N2/KCl. One hour after the addition of antibodies, cerebellar granule neurons were plated onto the coverslips and cultured for $24 \mathrm{hr}$, at which point the extent of neurite outgrowth was assessed.

The D5 antibody was also tested for interference with neurite promotion by intact tenascin-C splice variants. Large or small tenascin-C was bound to PLL-coated coverslips as described above. Coverslips were incubated for $1 \mathrm{hr}$ at $37^{\circ} \mathrm{C}$ with $100 \mu \mathrm{g} / \mathrm{ml}$ polyclonal D5 or fn6-8/fbg antibody. Then, cerebellar granule neurons were plated onto the coverslips and allowed to extend neurites for $24 \mathrm{hr}$.

\section{RESULTS}

\section{A short linear amino acid sequence in fnD promotes neurite outgrowth}

We investigated the hypothesis that a short linear amino acid sequence is responsible for neurite outgrowth promotion by $\mathrm{fnD}$, much as the sequence SIKVAV is responsible for neurite outgrowth promotion by the $\alpha 1$ helical domain of laminin-1 (Sephel et al., 1989). To do this, overlapping 15 amino acid synthetic 


\begin{tabular}{|c|c|c|}
\hline \multicolumn{3}{|c|}{$\begin{array}{l}\text { Table 2. Synthetic overlapping eight amino acid peptides spanning the } \\
\text { sequence of D4 and D5 }\end{array}$} \\
\hline Peptide & Sequence & $\begin{array}{l}\text { Coating } \\
\text { efficiency } \\
\left(\mathrm{pmol} / \mathrm{cm}^{2}\right)\end{array}$ \\
\hline D4a & SWTADEGV & $4.8 \pm 0.6$ \\
\hline $\mathrm{D} 4 \mathrm{~b}$ & ADEGVFDN & $5.3 \pm 0.9$ \\
\hline D4c/D5a & VFDNFVLK & $3.5 \pm 0.7$ \\
\hline D5b & NFVLKIRD & $5.9 \pm 0.5$ \\
\hline $\mathrm{D} 5 \mathrm{c}$ & KIRDTKKQ & $8.2 \pm 1.5$ \\
\hline D4c/D5a scrambled & FKVDLVNF & $4.4 \pm 0.9$ \\
\hline
\end{tabular}

PLL-coated glass coverslips were coated with fluorescein-conjugated peptides as indicated. At least three singular measurements were performed per peptide, and values obtained in three separate experiments were pooled and used for the determination of SDs.

peptides covering the sequence of fnD (Table 1) were tested for enhancement of neuronal process extension. PLL-coated coverslips were incubated with the synthetic peptides $(300 \mathrm{nM})$ overnight at $37^{\circ} \mathrm{C}$. We chose this concentration because it resulted in the maximal amount of peptide bound under these conditions (data not shown). Coating efficiencies for the peptides ranged from 3.6 to $12.4 \mathrm{pmol} / \mathrm{cm}^{2}$ under these conditions. (Table 1). Peptide solutions were washed away, and cerebellar granule neurons were plated onto the coverslips and allowed to extend neurites for $24 \mathrm{hr}$ in DMEM/N2/KCl.

Distributions of total neurite length for neurons cultured on each of the peptide substrates are presented in Figure $1 A$. Two peptides, D4 and D5, promoted neurite extension when bound to the coverslips. The other peptides had no effect on neurite outgrowth. This result cannot be attributed simply to higher substrate coating efficiencies for D4 and D5, as D8 and D10 (with coating efficiencies of $10.1 \pm 1.4 \mathrm{pmol} / \mathrm{cm}^{2}$ for D 8 and $12.4 \pm 2.5$ $\mathrm{pmol} / \mathrm{cm}^{2}$ for D10, as opposed to $5.2 \pm 1.1 \mathrm{pmol} / \mathrm{cm}^{2}$ for D4 and $7.4 \pm 0.8 \mathrm{pmol} / \mathrm{cm}^{2}$ for D5) did not facilitate process extension. Incubating the coverslips with peptides at a concentration of $1 \mu \mathrm{M}$ instead of $300 \mathrm{~nm}$ did not further enhance neurite outgrowth on D4 or D5 substrates, nor did it result in outgrowth promotion by any of the other substrate-bound peptides (data not shown). Furthermore, dissolving the peptides in HBSS instead of $1 \%$ acetic acid did not alter the distributions of total neurite length, indicating that the acetic acid used to prepare the peptide solutions did not denature peptides and led to loss of activity in the neurite outgrowth assays.

We have shown that fnA-D promotes outgrowth when it is bound as well as when it is soluble (Meiners and Geller, 1997; Meiners et al., 1999b). Therefore, the effects of soluble peptides were also evaluated. Peptides were bound first to coverslips, and excess peptide in solution (100 nM) was added. Neurons were then plated onto the coverslips and cultured in the presence of bound plus soluble peptides. Figure $1 A$ demonstrates that the addition of soluble D4 or D5 significantly enhanced outgrowth in comparison to values obtained on bound D4 or D5 alone, which is similar to what we have observed for fnA-D (Meiners and Geller, 1997). The effect was dose-dependent with a tendency toward saturation at $100 \mathrm{~nm}$ (data not shown), the amount used in all future experiments. None of the other peptides facilitated neurite outgrowth when soluble (data not shown).

Data from two additional independent experiments are presented in Figure $1 B$ to illustrate neurite outgrowth promotion from cerebellar granule neurons by the D4 and D5 peptides. We likewise analyzed data from three to four independent experiments in all other cases; however, data from only one representative experiment is shown in subsequent figures. Moreover, similar results were obtained in other experiments using cerebral cortical instead of cerebellar granule neurons (Fig. 1D), indicating that the actions of D4 and D5 were not restricted to one type of CNS neuron.

Figure $1 C$ presents images of cerebellar granule neurons cultured in the presence of bound or bound plus soluble D5. Neurites grown on bound D5 were visibly longer than neurites grown on PLL, and they were longer yet with the addition of soluble D5. Neurites grown in the presence of D5 also demonstrated enhanced branching in comparison to neurites grown on the control substrate, which is similar to what we have observed for cerebellar granule (data not shown) and cerebral cortical neurites grown in the presence of either fnA-D (Meiners et al., 1999b) or large tenascin-C (Meiners and Geller, 1997). Similar images were obtained for neurons cultured on D4 instead of D5. D4 corresponds to amino acids $1639-1653$, and D5 corresponds to amino acids 1646-1660 of human tenascin-C (GenBank accession number NP002151). Hence, a putative neurite outgrowth-promoting motif in $\mathrm{fnD}$ can be ascribed to amino acids $1646-1653$ of human tenascin-C, VFDNFVLK.

To confirm that VFDNFVLK can promote neurite outgrowth, overlapping eight amino acid peptides covering the sequence of D4 and D5 were tested in neurite outgrowth assays (Table 2). The peptides included D4a, the N-terminal portion of D4 (amino acids 1639-1646 of human tenascin-C); D4b, the internal portion of D4 (amino acids 1642-1649 of human tenascin-C); D4c/D5a, the shared C-terminal portion of D4 and N-terminal portion of D5 (amino acids 1646-1653 of human tenascin-C, VFDNFVLK); D5b, the internal portion of D5 (amino acids 1649-1656 of human tenascin-C), and D5c, the C-terminal region of D5 (amino acids $1653-1660$ of human tenascin-C). Peptides (300 nM) were bound to PLL-coated coverslips, and cerebellar granule neurons were plated onto the coverslips and allowed to extend neurites for $24 \mathrm{hr}$. In some cases, excess peptides in solution (100 nM) were added at the same time the neurons were plated. Of the bound peptides, only D4c/D5a enhanced neurite outgrowth (Fig. 2A); this peptide was as effective as D4 (Fig. 1) and D5 (Figs. 1, 2). Again, the results were not attributable to more D4c/D5a binding to the coverslips, because this peptide had the lowest coating efficiency of any of the eight amino acid peptides tested (Table 2). As with D4 and D5, the addition of excess soluble D4c/D5a resulted in a significant further enhancement of process extension (Fig. 2A), whereas the other eight amino acid peptides were ineffective when soluble (data not shown). These results demonstrate that the VFDNFVLK sequence can, by itself, promote neurite outgrowth. A scrambled peptide, FKVDLVNF, was ineffective in the neurite outgrowth assays when bound (Fig. $2 A$ ) or soluble (data not shown), indicating that the order of the amino acids is critical for biological activity.

Images of cerebellar granule neurons that were cultured in the presence of bound or bound plus soluble D4c/D5a are shown in Figure $2 B$. Images of cerebellar granule neurons cultured in the presence of D5 are shown for comparison. As for D5, neurites grown on bound D4c/D5a were visibly longer than neurites grown on PLL, and they were still longer with the addition of soluble D4c/D5a. Neurites grown on scrambled D4c/D5a (FKVDLVNF) were indistinguishable from neurites grown on PLL. 


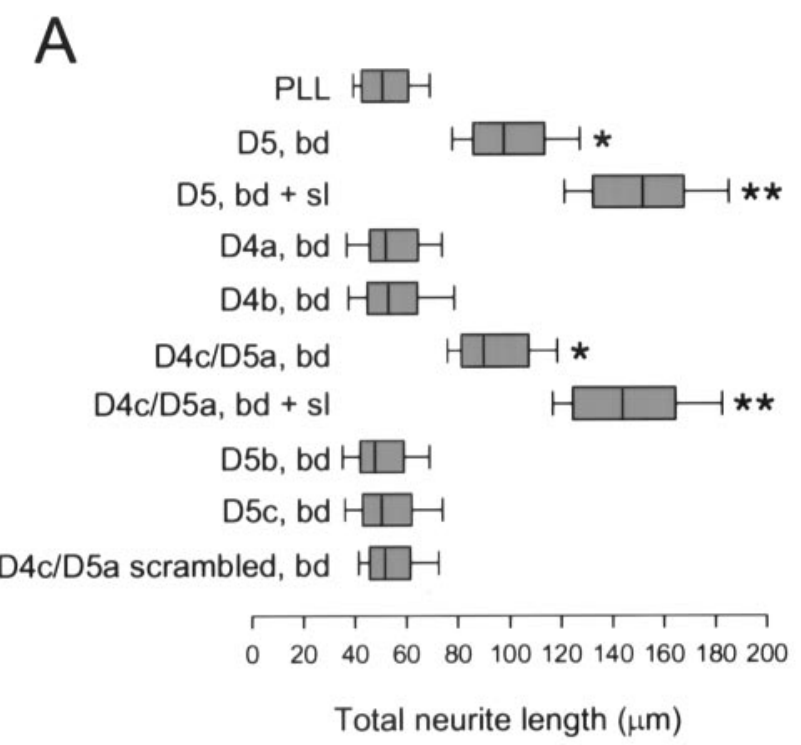

B
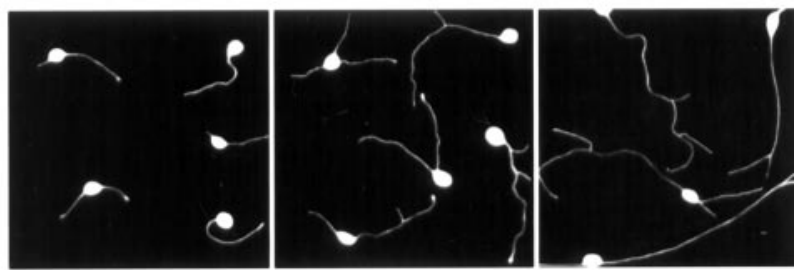

PLL

D5, bd

$\mathrm{D} 5, \mathrm{bd}+\mathrm{sl}$
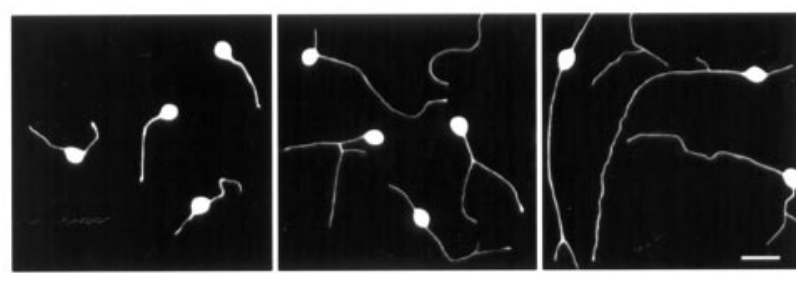

D4c/D5a

D4c/D5a, bd

scrambled, bd
$\mathrm{D} 4 \mathrm{c} / \mathrm{D5a}$, $\mathrm{bd}+\mathrm{sl}$

Figure 2. Promotion of neurite outgrowth by overlapping eight amino acid synthetic peptides covering the sequence of D4 and D5. A, Cerebellar granule neurons were cultured for $24 \mathrm{hr}$ on PLL-coated coverslips in the absence or presence of bound $(b d)$ or bound plus excess soluble $(b d+$ $s l)$ peptides. One representative experiment of three is shown. The D5 peptide is shown for comparison. Of the eight amino acid peptides tested, only the D4c/D5a peptide, which corresponds to amino acid sequence VFDNFVLK, promoted neurite outgrowth. Outgrowth was significantly enhanced on bound peptide in comparison to PLL $(* p<0.05$; Kolmogorov-Smirnov test). Excess soluble D4c/D5a significantly enhanced outgrowth still further in comparison to bound D4c/D5a $(* * p<0.05$; Kolmogorov-Smirnov test). A scrambled peptide, FKVDLVNF, had no affect on neurite extension. $B$, Images of cerebellar granule neurons cultured on PLL, D5, D4c/D5a, and scrambled D4c/D5a. As for D5, neurites grown on bound D4c/D5a were visibly longer than neurites grown on PLL, and they were still longer with the addition of soluble D4c/D5a. Neurites grown on scrambled D4c/D5a (FKVDLVNF) were indistinguishable from neurites grown on PLL. Scale bar, $15 \mu \mathrm{m}$.

\section{The neurite outgrowth-promoting peptide is active in tenascin-C}

To investigate the hypothesis that VFDNFVLK is also functional in tenascin- $\mathrm{C}$ and does not, for example, represent a

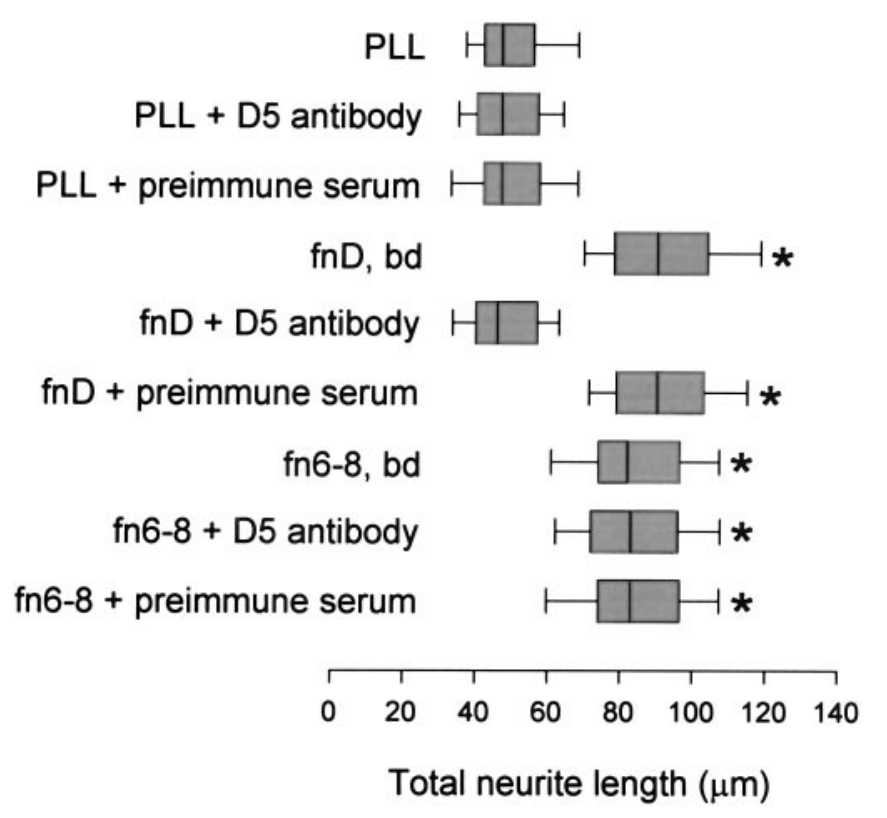

Figure 3. D5 is active in the context of fnD. Cerebellar granule neurons were cultured for $24 \mathrm{hr}$ on PLL-coated coverslips in the absence or presence of bound $\mathrm{fnD}$ or fn6-8 and an affinity-purified polyclonal antibody against synthetic peptide D5. One representative experiment of three is shown. FnD and fn6-8 both significantly increased neurite outgrowth in comparison to PLL ( $* p<0.05$; Kolmogorov-Smirnov test). The D5 antibody did not alter neurite outgrowth on PLL but completely blocked promotion of outgrowth by fnD. The effect of the $\mathrm{D} 5$ antibody was not replicated by preimmune serum. Neither the D5 antibody nor preimmune serum altered neurite outgrowth on fn6-8.

cryptic site, we first tested an affinity-purified polyclonal peptide antibody for obstruction of neurite outgrowth promotion by recombinant $\mathrm{fnD}$ and fn6-8 proteins. Fn6-8 is another tenascin- $\mathrm{C}$ region that promotes neurite outgrowth when substrate-bound but not when soluble (Meiners and Geller, 1997), but it does not share the VFDNFVLK sequence (Siri et al., 1991; Gherzi et al., 1995). The antibody used in these assays was prepared against the D5 peptide, which contains the VFDNFVLK sequence, instead of VFDNFVLK itself, because of high hydrophobicity and potentially low antigenicity of the latter. FnD and fn6-8 (300 nM) were bound to PLL-coated coverslips. Then, cerebellar granule neurons were cultured on the coverslips for $24 \mathrm{hr}$ in the presence or absence of D5 antibody, and process extension was quantified. $\mathrm{FnD}$ and fn6-8 (with coating efficiencies of $8.2 \pm 0.9$ and $7.3 \pm 1.4$ $\mathrm{pmol} / \mathrm{cm}^{2}$, respectively) both promoted neurite outgrowth when substrate-bound (Fig. 3), in agreement with our previous results using BHK cells as substrates instead of PLL-coated coverslips and an fnA-D recombinant protein instead of $\mathrm{fnD}$ (Meiners and Geller, 1997). The D5 antibody did not alter neurite outgrowth on PLL or fn6-8 but completely blocked neurite promotion by fnD. Preimmune serum from the rabbit immunized with D5 peptide did not alter process extension in any case. Like the peptides (Figs. 2, 3) and fnA-D (Meiners and Geller, 1997; Meiners et al., 1999b), fnD was active in both bound and soluble form, and the D5 antibody completely blocked the actions of the soluble protein as well (data not shown). These data support the hypothesis that the D5 peptide and the neurite outgrowth-promoting sequence VFDNFVLK is functional in the context of fnD.

We also tested the D5 antibody for interference of neurite outgrowth promotion by the largest splice variant of tenascin-C, 


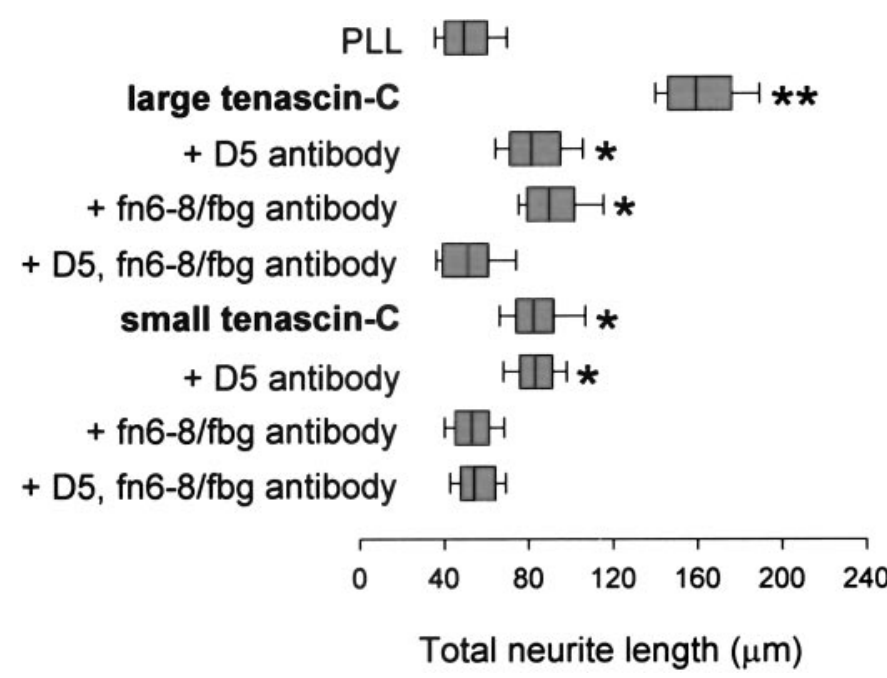

Figure 4. D5 is active in the context of tenascin-C. Cerebellar granule neurons were cultured for $24 \mathrm{hr}$ on PLL-coated glass coverslips in the absence or presence of the large or small tenascin-C splice variant and polyclonal D5 or fn6-8/fbg antibodies. One representative experiment of four is shown. Neurite outgrowth was enhanced on both large and small tenascin-C. Small tenascin-C significantly promoted outgrowth in comparison to PLL $\left({ }^{*} p<0.05\right.$; Kolmogorov-Smirnov test), whereas large tenascin-C significantly promoted outgrowth still further in comparison to small tenascin-C (**p $<0.05$; Kolmogorov-Smirnov test). The D5 antibody and fn6-8/fbg antibody both partially reduced neurite outgrowth on large tenascin-C, although outgrowth was still significantly greater than on the PLL control ( ${ }^{*} p<0.05$, Kolmogorov-Smirnov test). The combination of D5 antibody and fn6-8/fbg antibody was more effective than either antibody alone and reduced outgrowth on large tenascin-C to control values. In contrast, the D5 antibody did not affect neurite outgrowth on small tenascin-C, whereas the fn6-8/fbg antibody reduced neurite outgrowth to the control values. The combination of fn6-8/fbg antibody and D5 antibody was no more effective than fn6-8/ fbg antibody alone.

which contains fnD and the VFDNFVLK sequence, and the smallest splice variant, which does not. Large or small tenascin-C (300 nM) was bound to PLL-coated coverslips. Neurons were cultured for $24 \mathrm{hr}$ on the coverslips in the absence or presence of D5 antibody or polyclonal fn6-8/fbg antibody, which blocks the neurite outgrowth-promoting site in bound fn6-8 (Meiners and Geller, 1997).

Large and small tenascin-C (with coating efficiencies of $4.8 \pm$ 0.8 and $5.6 \pm 0.4 \mathrm{pmol} / \mathrm{cm}^{2}$, respectively) both promoted neurite outgrowth, although large tenascin-C promoted it to a greater extent, as we have previously reported (Meiners and Geller, 1997). The D5 antibody and the fn6-8/fbg antibody both partially blocked neurite outgrowth promotion by large tenascin-C (Fig. 4), although outgrowth was still greater than on the PLL control in the presence of these antibodies, in keeping with the fact that substrate-bound large tenascin-C promotes outgrowth through a site in fn6-8 as well as through the site in fnD (Meiners and Geller, 1997). When neurons were cultured on large tenascin-C in the presence of both the D5 antibody and the fn6-8/fbg antibody, outgrowth was indistinguishable from the PLL control, demonstrating that both neurite outgrowth-promoting sites in $\mathrm{fnD}$ and fn6-8 were completely blocked.

In contrast to the results with large tenascin-C, the D5 antibody failed to alter neurite outgrowth promotion by substrate-bound small tenascin-C (Fig. 4). Outgrowth was reduced to control values in the presence of the fn6-8/fbg antibody, in agreement with our previous results showing that the small splice variant

\begin{tabular}{|c|c|}
\hline Sequence & Species \\
\hline VEDN $\underline{F V L K}$ & Human \\
\hline VEDSEVLK & Pig \\
\hline IFDSFVIR & Rat \\
\hline IFDSFVIR & Mouse \\
\hline VFDSFVLK & Chicken \\
\hline
\end{tabular}

does not have any neurite outgrowth regulatory sites outside of the fn6-8 sequence (Meiners and Geller, 1997). The combination of fn6-8/fbg antibody and D5 antibody was no more effective than fn6-8 antibody alone. These results demonstrate that the D5 sequence is functional in the context of native tenascin- $C$, and more specifically, in the context of the large, fnD/VFDNFVLKcontaining tenascin-C splice variant.

\section{FD and FV are critical for the formation of the neurite outgrowth-promoting motif in FnD}

The neurite outgrowth-promoting peptide VFDNFVLK is derived from the sequence of human tenascin-C (Siri et al., 1991; Gherzi et al., 1995). This peptide contains 4 amino acids, $\mathrm{FD}$ and $\mathrm{FV}$, which are identical in tenascin-C sequences derived from all the species available in the GenBank (Table 3). To test the hypothesis that FD and FV are critical for the interaction with neurons, we made a recombinant $\mathrm{fnD}$ protein in which FD and was changed to "SP" and FV was changed to "GS." These substitutions were chosen so that polar amino acids were replaced with less polar amino acids and vice versa. Then, the mutant protein was compared with wild-type $\mathrm{fnD}$ in neurite outgrowth assays. In addition, a VSPNGSLK peptide was compared with VFDNFVLK for loss of function in outgrowth assays.

Proteins or peptides were bound to PLL-coated coverslips, and cerebellar granule neurons were plated onto the coverslips and cultured for $24 \mathrm{hr}$. Wild-type fnD and VFDNFVLK facilitated neuronal process extension but mutant fnD and VSPNGSLK did not, despite similar substrate coating efficiencies for the two proteins $\left(8.2 \pm 0.9 \mathrm{pmol} / \mathrm{cm}^{2}\right.$ for $\mathrm{fnD}$ and $6.7 \pm 0.8 \mathrm{pmol} / \mathrm{cm}^{2}$ for mutant fnD) and the two peptides $\left(3.5 \pm 0.7 \mathrm{pmol} / \mathrm{cm}^{2}\right.$ for VFDNFVLK and $8.9 \pm 1.2 \mathrm{pmol} / \mathrm{cm}^{2}$ for VSPNGSLK) (Fig. $5 A)$. Furthermore, the addition of excess soluble VSPNGSLK (100 nM) to bound VFDNFVLK did not alter neurite outgrowth on bound VFDNFVLK, suggesting that the former is merely inactive and not an antagonist or agonist for VFDNFVLK. Similar results were obtained in using VSANSSLK instead of VSPNGSLK, another synthetic peptide with alternations in FD and FV (data not shown). In contrast, an IFDSFVIR peptide (with a coating efficiency of $3.9 \pm 0.6 \mathrm{pmol} / \mathrm{cm}^{2}$ ), which represents the equivalent of VFDNFVLK in rat and mouse tenascin-C (Table 3), promoted neurite outgrowth to the same extent as VFDNFVLK. Excess IFDSFVIR in solution mimicked the actions of soluble VFDNFVLK and further enhanced outgrowth on bound VFDNFVLK. These results demonstrate that some or all of the four conserved amino acids FD and FV are important for formation of the active site in VFDNFVLK and the $f n D$ region of tenascin- $C$.

To define the respective roles of the FD and FV amino acids, we compared the activity of the peptides VSPNFVLK and 
A

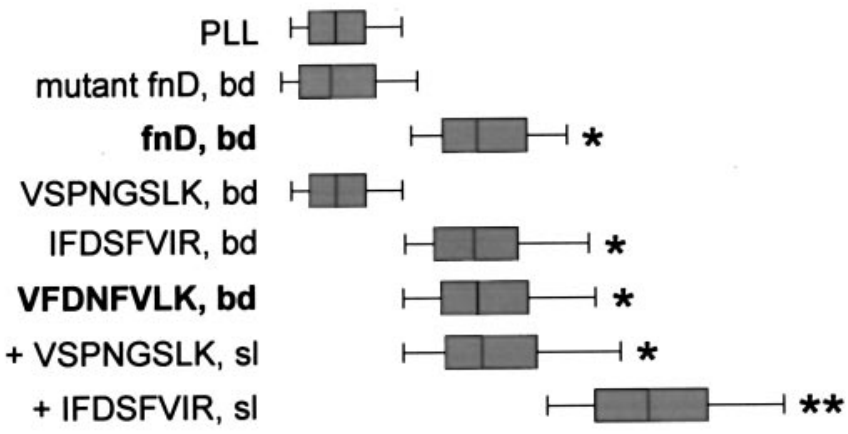

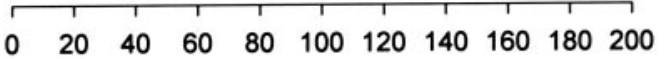

Total neurite length $(\mu \mathrm{m})$

B

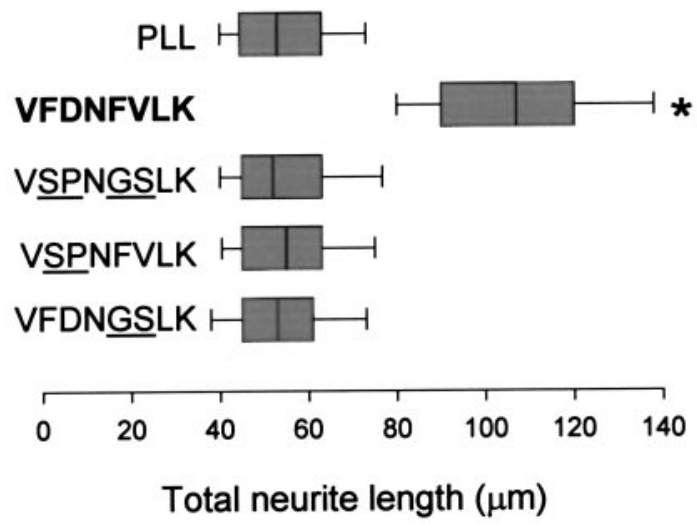

Figure 5. The conserved residues FD and FV in the sequence VFDNFVLK are critical for promotion of neurite outgrowth. $A$, Mutant fnD, wild-type fnD, VSPNGSLK, IFDSFVIR, or VFDNFVLK were bound to PLL-coated coverslips, and cerebellar granule neurons were plated onto the coverslips and allowed to extend processes for $24 \mathrm{hr}$. One representative experiment of four is shown. Mutant fnD and VSPNGSLK had no effect on neurite outgrowth, whereas wild-type fnD, IFDSFVIR, and VFDNFVLK significantly enhanced neurite outgrowth in comparison to PLL ( ${ }^{*} p<0.05$; Kolmogorov-Smirnov test). Soluble VSPNGSLK did not alter outgrowth on bound VFDNFVLK, whereas soluble IFDSFVIR resulted in a significant further enhancement of outgrowth on bound VFDNFVLK in comparison to bound VFDNFVLK alone $\left({ }^{* *} p<0.05\right.$; Kolmogorov-Smirnov test). $B$, VFDNFVLK, VSPNGSLK, VSPNFDLK, or VFDNGSLK were bound to PLL-coated coverslips, and cerebellar granule neurons were plated onto the coverslips and allowed to extend processes for $24 \mathrm{hr}$. One representative experiment of three is shown. Only VFDNFVLK significantly enhanced neurite outgrowth in comparison to PLL $\left({ }^{*} p<0.05\right.$; Kolmogorov-Smirnov test). None of the other peptides had any effect on neurite outgrowth.

VFDNGSLK to VFDNFVLK and VSPNGSLK in neurite outgrowth assays (Fig. 5B). Peptides were bound to PLL-coated glass coverslips, and cerebellar granule neurons were allowed to extend neurites for $24 \mathrm{hr}$ on the bound peptides. Like VSPNGSLK, VSPNFVLK and VFDNGSLK (with coating efficiencies of $5.7 \pm 0.7$ and $7.5 \pm 0.8 \mathrm{pmol} / \mathrm{cm}^{2}$, respectively) both demonstrated a loss of function in comparison to VFDNFVLK. Hence, both FD and FV are responsible for the facilitation of process extension by VFDNFVLK.
Table 4. VFDNFVLK and laminin-1 overcome neurite outgrowth inhibition by CSPGs

\begin{tabular}{lcl} 
& Substrate & \\
\cline { 2 - 3 } Addition & PLL & CSPG \\
\hline None & $47 \mu \mathrm{m}$ & $0^{\#}$ \\
VFDNFVLK, bd & $85 \mu \mathrm{m}^{*}$ & $55 \mu \mathrm{m}$ \\
VFDNFVLK, bd + sl & $136 \mu \mathrm{m}^{* *}$ & $93 \mu \mathrm{m}^{*}$ \\
Laminin-1, bd & $88 \mu \mathrm{m}^{*}$ & $47 \mu \mathrm{m}$ \\
Laminin-1, bd + sl & $74 \mu \mathrm{m}^{*}$ & $43 \mu \mathrm{m}$ \\
L1-Fc, bd & $128 \mu \mathrm{m}^{* *}$ & $17 \mu \mathrm{m}^{\#}$ \\
L1-Fc, bd + sl & $146 \mu \mathrm{m}^{* *}$ & $23 \mu \mathrm{m}^{\#}$
\end{tabular}

Cerebellar granule neurons were cultured for $24 \mathrm{~h}$ on the indicated substrate in the presence of bound (bd) or bound plus excess soluble (bd $+\mathrm{sl}$ ) VFDNFVLK, laminin-1, or L1-Fc. Data represent the median total neurite length for a sample of 100 neurons for each condition. One representative experiment of three is shown. Asterisks denote activity significantly greater than the PLL control $\left({ }^{*} p<0.05,{ }^{* *} p<\right.$ 0.005 , Kolmogorov-Smirnov test), whereas ${ }^{\#}$ denotes activity significantly less than the PLL control ( $p<0.005$, Kolmogorov-Smirnov test).

\section{VFDNFVLK overcomes neurite outgrowth inhibition by CSPGs}

Our next objective was to investigate whether VFDNFVLK could be used as a reagent to override neurite outgrowth inhibition by CSPGs in vitro, because CSPGs impair neuronal growth in culture (Snow et al., 1990) and are implicated in failed axonal regeneration in vivo (Gates et al., 1996; Davies et al., 1997). We also compared the effect of VFDNFVLK to that of the neurite outgrowth-promoting molecules laminin-1 and L1-Fc. A CSPG mixture consisting largely of neurocan, phosphacan, versican, and aggrecan $(50 \mu \mathrm{g} / \mathrm{ml})$; VFDNFVLK, laminin-1, or L1-Fc (300 $\mathrm{nM}$ ); or a combination of CSPGs and VFDNFVLK, laminin-1, or L1-Fc were bound to PLL-coated coverslips. Then, cerebellar granule neurons were cultured for $24 \mathrm{hr}$ on the coverslips. We used $50 \mu \mathrm{g} / \mathrm{ml}$ of the CSPG mixture rather than a specified molar concentration because native CSPGs with intact glycosaminoglycan side chains revealed a smear on SDS-PAGE gels, and accurate molecular weights could not be assigned (data not shown). The CSPG concentration was chosen because (1) it is maximally inhibitory to neurite outgrowth and (2) higher concentrations of CSPGs did not increase the amount of CSPG bound to the coverslip.

Table 4 demonstrates that the CSPG mixture was quite inhibitory in comparison to the PLL control; no outgrowth was observed on CSPGs, whereas the mean neurite length on the PLL control was $45 \mu \mathrm{m}$. Outgrowth on VFDNFVLK was similar to outgrowth on laminin-1; hence, bound VFDNFVLK (with a substrate coating efficiency of $3.5 \pm 0.7 \mathrm{pM} / \mathrm{cm}^{2}$ ) was as potent a neurite outgrowth promoter as bound laminin-1 (with a substrate coating efficiency of $4.5 \pm 1.0 \mathrm{pM} / \mathrm{cm}^{2}$ ). Neurite outgrowth on the combined CSPG/VFDNFVLK or the CSPG/laminin-1 substrate was comparable with the PLL control; thus, bound VFDNFVLK and laminin-1 both neutralized the outgrowth inhibitory properties of the CSPGs.

We found that considerably less peptide was bound to the coverslips in the presence of CSPGs; the substrate coating efficiency of VFDNFVLK was reduced to only $1.9 \pm 0.6 \mathrm{pm} / \mathrm{cm}^{2}$ in the combined CSPG/VFDNFVLK substrate. This suggests that higher amounts of VFDVFVLK might result in yet more neuronal process extension on CSPGs. In support of this hypothesis, addition of excess VFDNFVLK in solution (100 nM) to the mixed CSPG/VFDNFVLK substrate resulted in a significant 


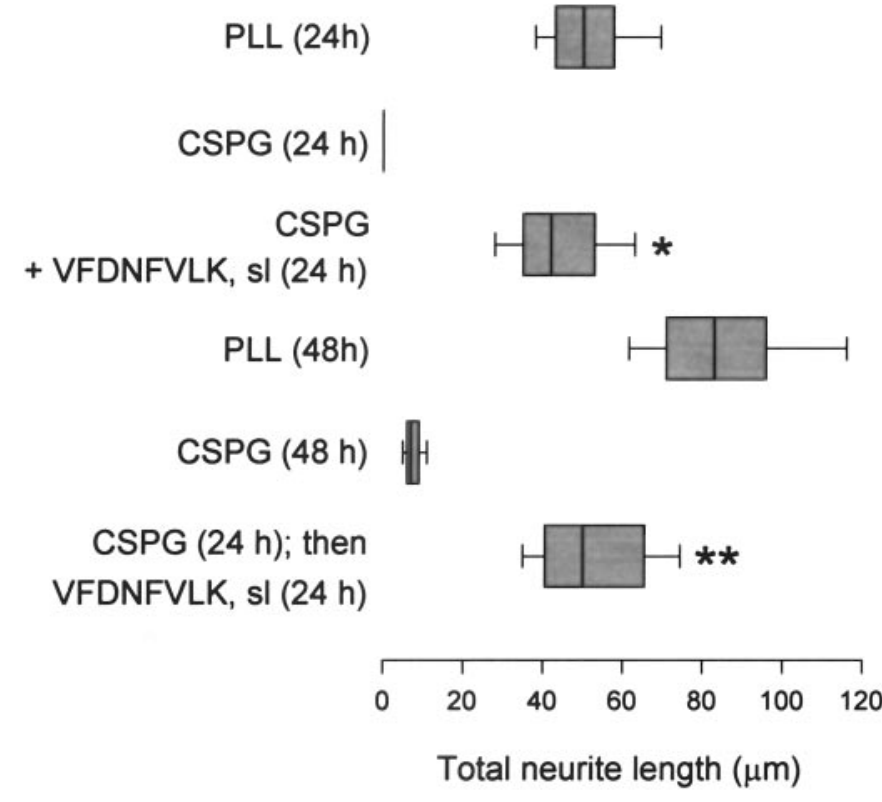

Figure 6. Soluble VFDNFVLK overcomes CSPG inhibition of neurite outgrowth. CSPGs were bound to PLL-coated coverslips, and cerebellar granule neurons were plated onto the coverslips and allowed to extend processes for 24 or $48 \mathrm{hr}$. One representative experiment of three is shown. In some experiments, VFDNFVLK in solution was added at the same time as plating neurons, and neurons were cultured on CSPGs for 24 $\mathrm{hr}$ in the presence of soluble VFDNFVLK. Neurites were significantly longer on CSPGs plus soluble peptide than on CSPGs alone after $24 \mathrm{hr}$ ( ${ }^{*} p<0.05$; Kolmogorov-Smirnov test). In other experiments, neurons were cultured on CSPGs for $24 \mathrm{hr}$, at which point VFDNFVLK in solution was added; then neurons were cultured for an additional $24 \mathrm{hr}$ in the presence of soluble VFDNFVLK. Neurites were significantly longer under these conditions than they were for neurons growing on CSPGs alone for $48 \mathrm{hr}\left({ }^{* *} p<0.05\right.$; Kolmogorov-Smirnov test).

further enhancement of neurite outgrowth, whereas addition of soluble laminin-1 (100 nM) to the CSPG/laminin-1 substrate had no further effect. In contrast to the results with VFDNFVLK and laminin-1, L1-Fc (with substrate coating efficiency of $6.2 \pm$ $0.9 \mathrm{pm} / \mathrm{cm}^{2}$ ) only partially neutralized the CSPGs, even though it was a more potent promoter of neurite outgrowth than either of the other two molecules in the bound form and demonstrated similar activity to VFDNFVLK in the soluble form. Thus, VFDNFVLK is not only a potent promoter of neurite growth by itself; it can also overcome outgrowth inhibition by CSPGs.

Because soluble VFDNFVLK can further enhance neurite outgrowth on a mixed CSPG/VFDVFNLK substrate, we investigated whether it could overcome inhibition of process extension on CSPGs alone. CSPGs $(50 \mu \mathrm{g} / \mathrm{ml})$ were bound to PLL-coated coverslips, and cerebellar granule neurons were plated onto the coverslips and cultured for $24 \mathrm{hr}$. In some cases, excess VFDNFVLK in solution (100 nM) was added at the same time the neurons were plated. No fluorescence was detected on coverslips incubated for $24 \mathrm{hr}$ with fluorescein-conjugated peptide (data not shown), demonstrating that VFDNFVLK did not bind to the CSPG substrate during the course of the experiment. As in Table 4, no process extension was observed on CSPGs after $24 \mathrm{hr}$. Addition of soluble VFDNFVLK resulted in a significant enhancement of neurite outgrowth, resulting in outgrowth similar to the PLL control (Fig. 6). In fact, median neurite length on CSPGs in the presence of soluble VFDNFVLK $(42 \mu \mathrm{m})$ was remarkably similar to the difference $(38 \mu \mathrm{m})$ between outgrowth
Table 5. VFDNFVLK overcomes neurite outgrowth inhibition by CSPGs in the context of large tenascin-C

\begin{tabular}{lcl} 
& Substrate & \\
\cline { 2 - 3 } Addition & PLL & CSPG \\
\hline None & $50 \mu \mathrm{m}$ & $0^{\#}$ \\
VFDNFVLK, bd & $86 \mu \mathrm{m}^{*}$ & $53 \mu \mathrm{m}$ \\
VFDNFVLK, bd + sl & $141 \mu \mathrm{m}^{* *}$ & $97 \mu \mathrm{m}^{*}$ \\
Fn6-8, bd & $78 \mu \mathrm{m}^{*}$ & $18 \mu \mathrm{m}^{\#}$ \\
Fn6-8, bd + sl & $11 \mu \mathrm{m}^{\#}$ & $0^{\#}$ \\
Large tenascin-C, bd & $149 \mu \mathrm{m}^{* *}$ & $69 \mu \mathrm{m}^{*}$ \\
$\quad+$ D5 antibody & $75 \mu \mathrm{m}^{*}$ & $19 \mu \mathrm{m}^{\#}$ \\
Large tenascin-C, bd $+\mathrm{sl}$ & $152 \mu \mathrm{m}^{* *}$ & $71 \mu \mathrm{m}^{*}$ \\
$\quad+$ D5 antibody & $11 \mu \mathrm{m}^{\#}$ & $0^{\#}$ \\
Small tenascin-C, bd & $76 \mu \mathrm{m}^{*}$ & $16 \mu \mathrm{m}$ \\
Small tenascin-C, bd $+\mathrm{sl}$ & $12 \mu \mathrm{m}^{\#}$ & $0^{\#}$
\end{tabular}

Cerebellar granule neurons were cultured for $24 \mathrm{~h}$ on the indicated substrate in the presence of bound $(b d)$ or bound plus excess soluble $(b d+s l)$ VFDNFVLK, fn6- 8 , large tenascin-C, or small tenascin-C. Data represent the median total neurite length for a sample of 100 neurons for each condition. One representative experiment of three is shown. Asterisks denote activity significantly greater than the PLL control $\left({ }^{*} p<0.05,{ }^{*} p<0.005\right.$, Kolmogorov-Smirnov test $)$, whereas ${ }^{\#}$ denotes activity significantly less than the PLL control ( $p<0.005$, Kolmogorov-Smirnov test).

on the combined VFDNVFLK/CSPG substrate $(55 \mu \mathrm{m})$ (Table 4 ) and outgrowth on the combined VFDVFVLK/CSPG substrate in the presence of soluble VFDNFVLK $(93 \mu \mathrm{m})$ (Table 4). Hence, soluble VFDNFVLK can, by itself, reverse CSPG inhibition of neuronal growth.

We also cultured cerebellar granule neurons on CSPGs for 24 $\mathrm{hr}$, added VFDNFVLK in solution, and then cultured the neurons in the presence of soluble peptide (100 nM) for another $24 \mathrm{hr}$ (Fig. 6). Neurites were significantly longer under these conditions than they were for neurons growing on CSPGs alone for $48 \mathrm{hr}$. Although some process extension was observed on CSPGs after $48 \mathrm{hr}$, it was quite meager in comparison to that observed on the PLL control at the same time point; hence, the neurites did not "acclimate" to CSPGs on their own. These results demonstrate that soluble VFDNFVLK can overcome neuronal growth inhibition by CSPGs, even when it is added after the neurons have already encountered the proteoglycans.

The ability of VFDNFVLK to overcome CSPG inhibition in the context of native tenascin-C was evaluated then, because tenascin-C and CSPGs are both upregulated on glial scars (McKeon et al., 1991; Gates et al., 1996). Our first step was to compare the ability of the other neurite outgrowth regulatory region of tenascin-C, fn6-8, to VFDNFVLK in overcoming CSPG inhibition. We found that bound fn6-8, like L1-Fc, only partially neutralized the CSPGs (Table 5). Excess soluble fn6-8, which itself impairs neurite outgrowth (Meiners and Geller, 1997), did not overcome any CSPG inhibition.

The activity of the largest and smallest tenascin-C splice variants was also assessed. Bound large tenascin-C, which facilitates neuronal process extension through one site in $\mathrm{fnD}$ and another in fn6-8 (Meiners and Geller, 1997) (Fig. 4A), was more effective than either bound VFDNFVLK or bound fn6-8 in promoting neurite outgrowth, either alone or in combination with CSPGs (Table 5). However, bound large tenascin-C was not as effective as bound plus excess soluble VFDNFVLK. In contrast, excess soluble large tenascin-C is inactive in neurite outgrowth assays because the neurite outgrowth-promoting site in soluble $\mathrm{fnD}$ "cancels" the neurite outgrowth inhibiting site in fn6-8 (Meiners 
and Geller, 1997). Therefore, soluble large tenascin-C, unlike soluble VFDNFVLK, did not further increase outgrowth on CSPGs. Hence, the peptide free of tenascin- $\mathrm{C}$ can have properties of its own. On the other hand, small tenascin- $\mathrm{C}$ regulates neurite outgrowth through fn6 -8 alone and mirrored the actions of fn6-8; it only partially neutralized the CSPG mixture when bound and did not overcome any CSPG inhibition when soluble. Blocking the large tenascin-C splice variant with the D5 antibody yielded results identical to those obtained for small tenascin-C and fn6-8, indicating that the difference in the ability of the splice variants to override proteoglycan inhibition was attributable to VFDNFVLK.

\section{DISCUSSION}

The region of tenascin-C containing only the alternately spliced fibronectin type III repeats, called fnA-D, dramatically increases neurite outgrowth in culture (Gotz et al., 1996; Meiners and Geller, 1997; Meiners et al., 1999b). Furthermore, the largest tenascin-C splice variant, which contains fnA-D, is preferentially expressed during phases of increased axonal growth in the developing CNS (Crossin et al., 1989; Tucker, 1993), suggesting that fnA-D stimulates neuronal growth in vivo as well. Efforts have focused on identifying the active site in fnA-D using recombinant proteins and blocking antibodies directed against different alternatively spliced FN-III repeats (Gotz et al., 1996, 1997; Meiners and Geller, 1997). These studies have implicated alternatively spliced FN-III repeat D as providing the stimulus for neuronal process extension. We now show that a short linear amino acid sequence in $\mathrm{fnD}$ derived from human tenascin-C, VFDNFVLK, is necessary and sufficient for outgrowth promotion from cerebellar granule neurons. VFDNFVLK is active by itself and also in the context of the large tenascin-C splice variant. This represents the most exact localization of a neurite outgrowthpromoting motif in tenascin-C.

Of the eight amino acids identified, FD and FV are identical in tenascin-C sequences derived from all the species available in GenBank. Moreover, our results demonstrate that FD and FV are critical for the interaction with neurons. On the other hand, the N-terminal "V" in VFDNFVLK is changed to "I" in some tenascin-C molecules (i.e., rat and mouse, Table 3), whereas the C-terminal "LK" is changed to "IR." These conservative amino acid changes do not modify the neurite outgrowth-promoting activity of the peptide, nor does the semiconservative amino acid change of "S" for "N" (Fig. 5), which is also found in some tenascin-C molecules (Table 3 ). However, it is quite possible that nonconservative changes in $\mathrm{V}, \mathrm{N}$, and $\mathrm{LK}$, in addition to nonconservative changes in FD and FV, would also render VFDNFVLK inactive.

Universal FN-III repeats 6-8 represents another region found in all tenascin-C splice variants that promotes neurite outgrowth when substrate-bound (Dorries et al., 1996; Meiners and Geller, 1997) but impairs it when soluble (Meiners and Geller, 1997). The permissive effect of bound fn6-8 is replicated by fn6 (Phillips et al., 1995; Gotz et al., 1996) but not by fn7-8 (Gotz et al., 1996), demonstrating that the outgrowth-promoting site likely resides in fn6. However, VFDNFVLK (and its homologous sequences in nonhuman tenascin-C molecules) is found only in $\mathrm{fnD}$ and is not shared by fn6, fn7, or fn8. This is consistent with data (Fig. 3) showing that an antibody directed against a 15 amino acid peptide containing VFDNFVLK completely blocked facilitation of neuronal process extension by fnD but did not alter outgrowth promotion by fn6-8. The VFDNFVLK sequence is likewise not shared by other neurite outgrowth-promoting molecules such as laminin-1, L1, fibronectin, thrombospondin, etc., as demonstrated by comparison of VFDNFVLK with other sequences available in the GenBank. Hence, VFDNFVLK is unique to the fnD region of tenascin-C. The inhibitory site in soluble fn6-8 is unknown, but it may be revealed to neurons because of conformational changes in bound versus soluble tenascin-C, as suggested by Lochter et al. (1991); alternatively, it may be obstructed by binding to the substrate and only revealed when fn6-8 is in solution. However, the latter seems unlikely because the PLLcoated coverslips used in this study have no specific receptors for any part of fn6-8, neurite outgrowth inhibiting or otherwise.

The question arises as to the neuronal receptor that interacts with VFDNFVLK. Neurite outgrowth promotion by substratebound tenascin- $\mathrm{C}$ is totally blocked by an antibody against the $\beta 1$ integrin chain (Varnum-Finney et al., 1995), suggesting that fn6-8 and VFDNFVLK both facilitate process extension via a $\beta 1$ integrin neuronal receptor. Indeed, work from VarnumFinney et al. (1995) has implicated the $\alpha 8 \beta 1$ integrin as the neuronal receptor for fn6-8, and our own work has shown that a blocking antibody against $\beta 1$ completely abolishes promotion of outgrowth by VFDNFVLK (S. Meiners, unpublished data). Hence, a $\beta 1$ integrin apparently mediates promotion of neurite outgrowth by a non-RGD site in fnD (VFDNFVLK), much as a $\beta 1$ integrin mediates cell attachment to a non-RGD site (AEIDGIEL) in the third FN-III repeat of tenascin-C (Yokosaki et al., 1994). Because the $\alpha 8$ blocking antibody used in the VarnumFinney et al. (1995) study only partially blocked neurite outgrowth promotion by native tenascin-C, this suggests that an additional $\alpha \beta 1$ heterodimer may mediate interactions with VFDNFVLK. Experiments are in progress in our laboratory to identify this $\alpha \beta 1$ heterodimer.

The crystal structure of fn 3 has been reported (Leahy et al., 1992), and AEIDGIEL includes portions of the exposed B-C loop and the adjacent $C \beta$ strand. "IDG" is localized on the exposed loop, and Yokosaki et al. (1998) provide evidence that IDG is important for binding to the $\alpha 9 \beta 1$ integrin. Alignment of the fn 3 and fnD sequences reveals that EIDGIEL in fn 3 corresponds to VFDNFVL in fnD. By extension, it is highly likely that the tripeptide FDN found in VFDNFVLK is appropriately localized on an exposed loop in $\mathrm{fnD}$ for an interaction with neurons. Our data (Fig. 5) indicate that FV, which is likely localized on a semiburied $\beta$ strand, is required for activity of VFDNFVLK. These amino acids may lend conformational stability rather than binding directly to neurons.

The third amino acid in both FDN and IDG is changed to S in some species (see above, also Yokosaki et al., 1998), strengthening the hypothesis that these sequences might be functional equivalents, both binding to the $\alpha 9 \beta 1$ integrin. However, $\alpha 9 \beta 1$ has not been detected in brain (Huang et al., 2000). It is also possible that FDN binds the $\alpha 4 \beta 1$ integrin, which is closely related to $\alpha 9 \beta 1$ on the basis of amino acid sequence (Takada et al., 1989). "FDN/S" is reminiscent of $\alpha 4 \beta 1$ recognition sequences (e.g., LDV, IDAP, KLDAP, IDSP) (Komoriya et al., 1991; Mould and Humphries, 1991; Clements et al., 1994; Moyano et al., 1997), which all contain a hydrophobic residue followed by an acidic residue, followed by a neutral amino acid. Alternatively, VFDNFVLK may bind an integrin other than $\alpha 4 \beta 1$ or $\alpha 9 \beta 1$. In any case, this sequence does not appear to interact with an RGD-specific receptor, because RGD peptides do not impair neurite outgrowth promotion by VFDNFVLK (data not shown).

Because of the potential of using small peptides as therapeutic 
reagents to stimulate nerve regeneration (Sakiyama et al., 1999), we evaluated the ability of VFDNFVLK to promote neurite outgrowth in combination with CSPGs. CSPGs are upregulated on glial scars (McKeon et al., 1991; Pindzola et al., 1993), and the preponderance of evidence indicates that they are inhibitory to axonal regrowth in brain (Gates et al., 1996) and spinal cord (Zuo et al., 1998) injury. We found that VFDNFVLK significantly enhanced neurite outgrowth on proteoglycans and was more effective than other neurite outgrowth-promoting substrate molecules, including laminin-1, L1-Fc, and substrate-bound tenascin-C fn6-8, demonstrating a possible role for VFDNFVLK in regenerative strategies. However, CSPGs are not the only molecules that impair axonal regrowth after CNS injury; myelin-derived molecules such as myelin-associated glycoprotein (Shen et al., 1998) and Nogo-A (Chen et al., 2000) have also been suggested to have an inhibitory role. Hence, VFDNFVLK may find use as part of a regeneration mixture that also includes, for example, blockers of these inhibitory myelin molecules.

The expression of tenascin- $\mathrm{C}$ is also upregulated along with CSPGs on the glial scar. Therefore, we evaluated whether VFDNFVLK could overcome CSPG inhibition in the context of native tenascin-C. Our results demonstrated that the largest tenascin-C splice variant was far more effective than the smallest in increasing outgrowth on CSPGs, and that this was attributable to the presence of VFDNFVLK. This might suggest that large tenascin-C functions to enhance neuronal regeneration after CNS injury. On the other hand, a careful study of differential expression of tenascin-C splice variants has not been conducted after injury, and increased tenascin- $\mathrm{C}$ expression is sometimes but not always correlated with increased axonal regrowth in vivo (Gates et al., 1996; Deller et al., 1997; Zhang et al., 1997). It could be that the large tenascin-C splice variant is not always prevalent at the lesion site, or that the receptor for VFDNFVLK is not activated or upregulated in all CNS neurons after injury. Alternatively, given its multidomain structure, tenascin- $\mathrm{C}$ may assume a conformation in vivo such that inhibitory and promotional domains both interact with neurons, leading to no net effect on axonal regrowth. In the latter case, VFDNFVLK would find greater utility than large tenascin-C as part of a regeneration mixture to overcome CSPG inhibition of neurite outgrowth.

In summary, we have identified an eight amino acid sequence, VFDNFVLK, in alternatively spliced FN-III repeat D of human tenascin-C that promotes neurite outgrowth by itself and also in the context of tenascin-C. The biological activity depends on amino acids FD and FV. This peptide also overcomes inhibition of neurite outgrowth in vitro by CSPGs, suggesting that it might find applicability as a reagent to promote neurite growth in otherwise inhibitory environments.

\section{REFERENCES}

Aota S, Nomizu M, Yamada KM (1994) The short amino acid sequence Pro-His-Ser-Arg-Asn in human fibronectin enhances cell-adhesive function. J Biol Chem 269:24756-24761.

Aukhil I, Joshi P, Yan Y, Erickson HP (1993) Cell- and heparin-binding domains of the hexabrachion arm identified by tenascin expression proteins. J Biol Chem 268:2542-2553.

Bartsch S, Bartsch U, Dorries U, Faissner A, Weller A, Ekblom P, Schachner M (1992) Expression of tenascin in the developing and adult cerebellar cortex. J Neurosci 12:736-749.

Bronner-Fraser M (1988) Distribution and function of tenascin during cranial neural crest development in the chick. J Neurosci Res 21:135-147.

Chen MS, Huber AB, van der Haar ME, Frank M, Schnell L, Spillman AA, Christ F, Schwab ME (2000) Nogo-A is a myelin-associated neurite outgrowth inhibitor and an antigen for monoclonal antibody IN-1. Nature 403:434-439.
Clements JM, Newham P, Shepherd M, Gilbert R, Dudgeon TJNLA, Edwards RM, Berry L, Brass A, Humphries MJ (1994) Identification of a key integrin-binding sequence in VCAM-1 homologous to the LDV active site in fibronectin. J Cell Sci 107:2127-2135.

Crossin KL, Hoffman S, Tan SS, Edelman GM (1989) Cytotactin and its proteoglycan ligand mark structural and functional boundaries in somatosensory cortex of the early postnatal mouse. Dev Biol 136:381-392

Davies SJ, Fitch MT, Memberg SP, Hall AK, Raisman G, Silver J (1997) Regeneration of adult axons in white matter tracts of the central nervous system. Nature 390:680-683.

Deller T, Haas CA, Naumann T, Joester A, Faissner A, Frotscher M (1997) Up-regulation of astrocyte-derived tenascin-C correlates with neurite outgrowth in the rat dentate gyrus after unilateral entorhinal cortex lesion. Neuroscience 81:829-846.

Dorries U, Taylor J, Xioa Z, Lochter A, Montag D, Schachner M (1996) Distinct effects of recombinant tenascin domains on neuronal cell adhesion, growth cone guidance, and neuronal polarity. J Neurosci Res 43:420-438.

Erickson HP, Briscoe G (1995) Tenascin, laminin, and fibronectin produced by cultured cells. In: Extracellular matrix: a practical approach (Haralson MA, Hassell JR, eds). Oxford: Oxford UP.

Fernaud-Espinosa I, Nieto-Sampedro M, Bovolenta P (1998) A neurite outgrowth-inhibitory proteoglycan expressed during development is similar to that isolated from adult brain after isomorphic injury. J Neurobiol 36:16-29.

Gates MA, Fillmore H, Steindler DA (1996) Chondroitin sulfate proteoglycan and tenascin in the wounded adult mouse neostriatum in vitro: dopamine neuron attachment and process outgrowth. J Neurosci 16:8005-8018.

Gherzi R, Carnemolla B, Siri A, Ponassi M, Balza E, Zardi L (1995) Human tenascin gene. Structure of the 5'-region, identification, and characterization of the transcription regulatory sequences. J Biol Chem 270:3429-3434.

Gotz B, Scholze A, Clement A, Joester A, Schutte K, Wigger F, Frank R, Spiess E, Ekblom P, Faissner A (1996) Tenascin-C contains distinct adhesive, anti-adhesive, and neurite outgrowth promoting sites for neurons. J Cell Biol 132:681-699.

Gotz M, Bolz J, Joester A, Faissner A (1997) Tenascin-C synthesis and influence on axon growth during rat cortical development. Eur J Neurosci 9:496-506.

Grumet M, Hoffman S, Crossin KL, Edelman GM (1985) Cytotactin, an extracellular matrix protein of neural and non-neural tissues that mediates glia-neuron interaction. Proc Natl Acad Sci USA 82:8075-8079.

Huang XZ, Wu JF, Ferrando R, Lee JH, Wang YL, Farese Jr RV, Sheppard D (2000) Fatal bilateral chylothorax in mice lacking the integrin alpha9beta1. Mol Cell Biol 20:5208-5215.

Kaplony A, Zimmermann DR, Fischer RW, Imhof BA, Odermatt BF, Winterhalter KH, Vaughan L (1991) Tenascin Mr 220000 isoform expression correlates with corneal cell migration. Development 112:605-614.

Komoriya A, Green LJ, Mervic M, Yamada SS, Yamada KM, Humphries MJ (1991) The minimal essential sequence for a major cell type-specific adhesion site (CS1) within the alternatively spliced type III connecting segment domain of fibronectin is leucine-aspartic acidvaline. J Biol Chem 266:15075-15079.

Leahy DJ, Hendrickson WA, Aukhil I, Erickson HP (1992) Structure of a fibronectin type III domain from tenascin-C by MAD analysis of the selenomethionyl protein. Science 258:987-991.

Lochter A, Vaughan L, Kaplony A, Prochiantz A, Schachner M, Faissner A (1991) J1/tenascin in substrate-bound and soluble form displays contrary effects on neurite outgrowth. J Cell Biol 113:1159-1171.

McKeon RJ, Schreiber RC, Rudge JS, Silver J (1991) Reduction of neurite outgrowth in a model of glial scarring following CNS injury is correlated with the expression of inhibitory molecules on reactive astrocytes. J Neurosci 11:3398-3411.

Meiners S, Geller HM (1997) Long and short splice variants of human tenascin differentially regulate neurite outgrowth. Mol Cell Neurosci 10:100-116.

Meiners S, Mercado ML, Kamal MS, Geller HM (1999a) Tenascin-C contains domains that independently regulate neurite outgrowth and neurite guidance. J Neurosci 19:8443-8453.

Meiners S, Powell EM, Geller HM (1999b) Neurite outgrowth promotion by the alternatively spliced region of tenascin-C is influenced by cell type specific binding. Matrix Biol 18:75-87.

Mould A, Humphries MJ (1991) Identification of a novel recognition sequence for the integrin alpha 4 beta 1 in the COOH-terminal heparin-binding domain of fibronectin. EMBO J 10:4089-4095.

Moyano JV, Carnemolla B, Dominguez-Jimenez C, Garcia-Gila M, Albar JP, Sanchez-Aparicio P, Leprini A, Querze G, Zardi L, Garcia-Pardo A (1997) Fibronectin type III5 repeat contains a novel cell adhesion sequence, KLDAPT, which binds activated alpha4beta1 and alpha4beta7 integrins. J Biol Chem 272:24832-24836.

Nur-e-kamal MS, Varga M, Maruta H (1993) The GTPase-activating NF1 fragment of 91 amino acids reverses v-Ha-Ras-induced malignant phenotype. J Biol Chem 268:22331-22337. 
Pavia J, Alberch J, Alvarez I, Toledano A, de Ceballos ML (2000) Repeated intracerebroventricular administration of beta-amyloid(25$35)$ to rats decreases muscarinic receptors in cerebral cortex. Neurosci Lett 278:69-72.

Petroski RE, Geller HM (1994) Selective labeling of embryonic neurons cultured on astrocyte monolayers with 5(6)-carboxyfluorescein diacetate (CFDA). J Neurosci Methods 52:23-32.

Phillips GR, Edelman GM, Crossin KL (1995) Separate cell binding sites within cytotactin/tenascin differentially promote neurite outgrowth. Cell Adhes Commun 3:257-271.

Pindzola RR, Doller C, Silver J (1993) Putative inhibitory extracellular matrix molecules at the dorsal root entry zone of the spinal cord during development and after root and sciatic nerve lesions. Dev Biol 156:34-48.

Prieto AL, Jones FS, Cunningham BA, Crossin KL, Edelman GM (1990) Localization during development of alternatively spliced forms of cytotactin mRNA by in situ hybridization. J Cell Biol 111:685-698.

Sakiyama SE, Schense JC, Hubbell JA (1999) Incorporation of heparinbinding peptides into fibrin gels enhances neurite extension: an example of designer matrices in tissue engineering. FASEB J 13:2214-2224.

Sephel GC, Tashiro KI, Sasaki M, Greatorex D, Martin GR, Yamada Y, Kleinman HK (1989) Laminin A chain synthetic peptide which supports neurite outgrowth. Biochem Biophys Res Commun 162:821-829.

Shen YJ, DeBellard ME, Salzer JL, Roder J, Filbin MT (1998) Myelinassociated glycoprotein in myelin and expressed by Schwann cells inhibits axonal regeneration and branching. Mol Cell Neurosci 12:79-91.

Siri A, Carnemolla B, Saginati M, Leprini A, Casari G, Baralle F, Zardi L (1991) Human tenascin: primary structure, pre-mRNA splicing patterns and localization of the epitopes recognized by two monoclonal antibodies. Nucleic Acids Res 19:525-531.
Snow DM, Lemmon V, Carrino DA, Caplan AI, Silver J (1990) Sulfated proteoglycans in astroglial barriers inhibit neurite outgrowth in vitro. Exp Neurol 109:111-130.

Steindler DA, Cooper NG, Faissner A, Schachner M (1989) Boundaries defined by adhesion molecules during development of the cerebral cortex: the $\mathrm{J} 1 /$ tenascin glycoprotein in the mouse somatosensory cortical barrel field. Dev Biol 131:243-260.

Takada Y, Elices MJ, Crouse C, Hemmler ME (1989) The primary structure of the alpha 4 subunit of VLA-4: homology to other integrins and a possible cell-cell adhesion function. EMBO J 8:1361-1368.

Tucker RP (1993) The in situ localization of tenascin splice variants and thrombospondin 2 mRNA in the avian embryo. Development 117:347-358.

Varnum-Finney B, Venstrom K, Muller U, Kypta R, Backus C, Chiquet M, Reichardt LF (1995) The integrin receptor alpha 8 beta 1 mediates interactions of embryonic chick motor and sensory neurons with tenascin-C. Neuron 14:1213-1222.

Yokosaki Y, Palmer EL, Prieto AL, Crossin KL, Bourdon MA, Pytela R, Sheppard D (1994) The integrin alpha 9 beta 1 mediates cell attachment to a non-RGD site in the third fibronectin type III repeat of tenascin. J Biol Chem 269:26691-26696.

Yokosaki Y, Matsuura N, Higashiyami S, Murakami I, Obara M, Yamakido M, Shigeto N, Chen J, Sheppard D (1998) Identification of the ligand binding site for the integrin a9b1 in the third fibronectin type III repeat of tenascin-C. J Biol Chem 273:11423-11428.

Zhang Y, Winterbottom JK, Schachner M, Lieberman AR, Anderson PN (1997) Tenascin-C expression and axonal sprouting following injury to the spinal dorsal columns in the adult rat. J Neurosci Res 49:433-450.

Zuo J, Neubauer D, Dyess K, Ferguson TA, Muir D (1998) Degradation of chondroitin sulfate proteoglycan enhances the neurite-promoting potential of spinal cord tissue. Exp Neurol 154:654-662. 